\title{
KAWENTENAN CAMPUH KODE RING KORAN BALI POST PAHAN BALI ORTI RAHINA REDITE SASIH JULI-DESEMBER WARSA 2016
}

\author{
I Wyn. Pandi Yasa ${ }^{1}$, I. B. Rai ${ }^{1}$, I. B. Md. Ludy Paryatna ${ }^{2}$ \\ Jurusan Pendidikan Bahasa Bali \\ Universitas Pendidikan Ganesha \\ Singaraja, Indonesia \\ e-mail: \{pandiyasa@gmail.com,bagus.rai@undiksha.ac.id, \\ idabagusludy@gmail.com\}@undiksha.ac.id
}

\begin{abstract}
Kuub
Tetilikan puniki matetujon mahbahang (1) soroh campuh kode sane wenten ring rong Bencingah koran Bali Post pahan Bali Orti rahina redite sasih Juli-Desember warsa 2016, (2) Basa sane wenten ring rong Bencingah koran Bali Post pahan Bali Orti rahina redite sasih Juli-Desember warsa 2016, lan (3) sane ngawinang wenten kapanggihin campuh kode ring koran Bali Post pahan Bali Orti rahina redite sasih JuliDesember warsa 2016 utaminyane ring rong Bencingah. Jejering tetilikan inggih punika koran Bali Post saking sasih Juli-Desember warsa 2016. Panandang tetilikan inggih punika campuh kode. Kramaning tetilikan sane kaanggen minakadi dokumentasi lan sadu wicara. Data tureksa sane kaanggen sakadi mastikayang data, reduksi data, nyorohang data lan panyutetan. Pikolih tetilikan minakadi, (1) soroh campuh kode minakadi, 104 data marupa campuh kode manut wit basa lan 110 data sane marupa campuh kode manut kerta basa. (2) Basa sane ngawinang wentennyane campuh kode inggih punika basa Bali, basa Indonesia lan basa Inggris. (3) Sane ngawinang wenten kapanggihin campuh kode inggih punika sangkaning kawentenan (keterbatasan) ring basa, pacampuhan basa punika sampun lumrah kauningin saha kaanggen olih kramane ring Bali, lan mangda dangan karesepang olih krama Bali utamanyane.
\end{abstract}

Kruna Jejaton: campuh kode, koran Bali Post

\begin{abstract}
Abstrak
Penelitian ini bertujuan menguraikan (1) jenis campur kode dalam kolom Bencingah koran Bali Post bagian Bali Orti yang terbit pada hari minggu dari bulan Juli-Desember tahun 2016, (2) bahasa yang ada dalam kolokm Bencingah koran Bali Post bagian Bali Orti yang terbit pada hari minggu dari bulan Juli-Desember tahun 2016, (3) yang menyebabkan adanya campur kode dalam koran Bali Post bagian Bali Orti yang terbit pada hari minggu dari bulan Juli-Desember tahun 2016 khususnya dalam kolom Bencingah. Subjek penelitian adalah koran Bali Post bagian Bali Orti yang terbit pada hari minggu dari bulan Juli-Desember tahun 2016. Objek penelitian adalah campur kode. Metode penelitian yang digunakan yaitu dokumentasi dan wawancara. Analisis data yang digunakan seperti identifikasi data, reduksi data, klasifikasi data dan kesimpulan. Hasil penelitian yaitu, (1) jenis campur kode seperti, 104 data berupa campur kode menurut asal bahasa dan 110 data yang berupa campur kode menurut tingkatan kata (2) Bahasa yang menyebabkan campur yaitu bahasa Bali, Bahasa Indonesia dan Bahasa Inggris, (3) yang menyebabkan adanya campur kode yaitu karena keterbatasan bahasa, pencampuran bahasa sudah lumrah
\end{abstract}


diketahui serta digunakan oleh masyarakat Bali dan supaya mudah dipahami oleh masyarakat Bali pada khususnya.

Kata Kunci : campur kode, koran Bali Post

\begin{abstract}
This research can describe (1) the type of mixed code in Bali Post newspaper part of Bali Orti which is published on Sunday from July to December 2016, (2) the language causing mixed code in Bali Post newspaper part of Bali Orti which was published on Sunday from July to December of 2016, (3) which caused a mixed code in the Bali Post newspaper part of Bali Orti which was published on Sunday from July to December 2016. Research subjects were Bali Post newspaper part of Bali Orti published on Sunday from July to December of 2016. The object of research is the interc code. The research method used is documentation and interview. Analysis of data used such as data identification, data reduction, data data and decision. The results of the study were (1) mixed code types such as, 104 data with language and language code derived from the language and 110 data which is code according to word (2) language containing Balinese language, Indonesian and English language, (3) which is due to the mixed code because the language, the language that has been commonly published also the people of Bali and easily easy to understand.
\end{abstract}

Keywords: mixed code, Bali Post newspaper

\section{PURWAKA}

Kawentenan basa ring kauripan jadma madue kawigunan sane dahat mautama. Sinalih tunggil kawigunan basa inggih punika pinaka piranti sane kaanggen mabebaosan olih para jadma, sane kaanggen nguningayang daging pikayunan sane dados pikobet, pabesen, lan tetuladan olih jadma siosan. Yening pinehang jadma lan kauripannyane nenten wenten basa, sampun sinah jadma punika nenten prasida ngmargiang kauripannyane santukan nenten wenten piranti sane kaanggen mabebaosan (berkomunikasi) sareng kulawarga lan semeton sane lianan. Tatujon utama saking wentenyane basa inggih punika mangda jadma utawi krama ring kahuripan puniki dangan mabebaosan (berkomunikasi). Basa kaangen olih jadma ring makasami pamargin kauripan (Aslinda lan Leni, 2007: 1).

Ring jagat sane jimbar puniki makeh pisan wenten basa. Basa-basa punika metu sangkaning jadma sane mabebaosan punika kahanannyane malianan, akeh lan madue pikobet sane mabinayan. Sakadi sinalih tunggilnyane ring panegara Indonesia. Ring panegara Indonesia puniki wenten makudangkudang basa daerah sane kaduenang. Sinalih tunggilnyane basa Bali, basa Bali pinaka basa lbu sane kaanggen mabebaosan olih krama Bali. Basa Bali taler dados sinalih tunnggil basa sane kalintang luih tur mautama sangkaning aksaran ipun. Basa Bali kadadosang basa utama sane kaangen ring sajeroning pamargin kauripan olih krama Bali. Sakadi napi sane sampun kauningin, Bali kaloktah antuk seni lan budayanyane.

Nanging ring aab sakadi mangkin, kawentenan basa Bali sampun sayan rered. Makeh krama Bali utamannyane para yowana nenten uning lan nenten kayun nganggen basa Bali ring sajeroning mabebaosan. Kawentenan puniki duaning wentennyane panglimbak aab sane tan pawates sane ngawinang basa Bali sayan kagingsirang antuk basa anyar siosan. Akeh pisan sane mangkin kapanggih krama Bali sane nenten nganggen basa Bali pinaka basa sarahin. Panglimbak parindikan puniki gelis pisan ring krama Bali, ring Bali sane mangkin makeh pisan rerama sane ngicenin pianaknyane 
mangda ngutamayang malajah basa Indonesia utawi basa dura negara siosan tur nyampingang basa Bali. Parindikan puniki pastika pacang ngawinang kawentenan basa Bali sayan kaengsapang riantukan sampun kagentosin antuk kawentenan basa-basa siosan sane kabakta olih pamargin panglimbak jagat. Siosan ring punika taler sayan akeh basa sane metu saking krama saha dangan katampi ring kahuripan krama Bali, sakadi ring Sastra Bali Anyar, ring media sosial, tembang-tembang Bali, ring paruman miwah sane lianan. Duaning asapunika basa Bali patut kalestariang saking mangkin olih samian krama Bali antuk makudang-kudang utsaha sane prasida mikukuhang basa Bali. Nampenin pikobet punika sane mangkin makudangkudang utsaha sampun karincikang turmaning kalaksanayang mangda basa Bali punika tetep ajeg miwah lestari. Utsaha punika nenten wantah nglestariang pangweruhnyane kemanten, nanging saking pamaosnyane taler patut kauratiang antuk ngamedalang kahanan sane ngawinang pamaosnyane stata nganggen basa Bali (Wijana, 2012: 11).

Parindikan sane ngawinang basa

Bali sane sampun sayan kaengsapang nenten ja sios wantah wentennyane basabasa lianan sane ngranjing ring tengahing basa Bali. Lianan ring punika basa-basa lianan sane ngranjing ring tengahing basa Bali punika prasida dangan katampi olih krama Bali. Punika sane ngawinang basa Bali punika dangan kagentosin antuk basa-basa sane lianan. Saking parindikan punika pacang medal basa-basa sane anyar ring tengahing basa Bali. Kawentenan sekadi punika kabaos campuh kode yening manut widia linguistik. Campuh kode ingih punika parindikan kalih kode basa sane kaanggen ring siki lengkara. Campuh kode inggih punika pacampuhan basa utawi langkung basa ring sajeroning tindak tutur (Nababan, 1991:32).

kawentenan campuh kode medal yening sang pamaos basa utama sane kaanggen antuk basa-basa sane lianan, sakadi mebaosan basa bali ring tengah bebaosan punika wenten basa
Indonesiannyane. Campuh kode ketahnyane kaanggen ring bebaosan informal. Yadiastun sakadi asapunika, campuh kode nenten prasida kabaosang iwang santukan sampun katrima olih krama. Dadosnyane, campuh kode punika medal sangkaning parisolah sang sane mabaos, sakadi wewidangan parikrama, kawagedan mabasa miwah kawigunan bebaosan. Lianan ring punika, karumaketan sang sane mabaos, genah miwah galah informal, miwah kaanutan basa utawi nenten wentennyane basa sane manut kaanggen, dados parindikan sane prasida ngamedalang campuh kode. Kawentenan campuh kode prasida ngawinang basa Bali sayan ical lan kaengsapang olih krama Bali.

Media massa puniki wenten ring wewidangan media massa lisan lan sesuratan. Koran pinaka sinalih tunggil sane ngranjing ring media massa sesuratan. Koran puniki akeh madaging sakancan orti, parindikan sane wenten sane matetujon mangda sang sane ngwacen koran punika prasida uning napi gatra sane wenten ring rahinane mangkin. Koran puniki ngranjing ring media sesuratan santukan orti puniki kasurat lan kacetak ring kertas.

Koran inggih punika kertas sane kacetak sane madaging orti saking krama, cecirenyane medal manut galahnyane, kahananyane umum, daging ortinyane anyar sane mapaiketan sareng kauripan ring jagat mangda kauningin olih sang pangwacen. Koran prasida kabos pinaka media massa sane pinih lingsir sadurung wentennyane film, radio lan televisi (Cangara, 2012:141). Sakadi sane sampun kauningin, koran punika wenten sane medal nyabran rahina lan wenten sane medal nyabran awuku. Ring Bali koran sane medal nyabran rahina punika koran sane nganggen basa Indonesia lan koran sane medal ring rahina Redite punika nganggen basa Bali ring pahan Bali Orti. Indike punika becik pisan kaanggen malajah ring para yowanane sakadi mangkin sane kirang pisan uning indik kosabasa basa Bali. Nanging patut taler kauratiang ring koran sane medal rahina redite punika nenten sami ngangge 
basa Bali, akeh sane madaging lianan ring basa Bali santukan bebaosannyane keni iusan globalisasi sakadi ring kolom bebantenan, upacara, profil, kruna, bencingah, kesusastraan miwah sane lianan.

Majalaran antuk napi sane sampun katlatarang ring ajeng, panilik ngamargiang tetilikan sane mamurda "Kawentenan Campuh Kode Ring Koran Bali Post Pahan Bali Orti Rahina Redite Sasih Juli-Desember Warsa 2016".

Sajeroning tetilikin sane jagi kalaksanayang, panilik mautsaha ngereh makudang-kudang pikobet sane mapaiketan sareng dadalan pikobet tetilikan puniki. Pikobet sane karereh mangda mapaiketan sareng kawentenan campuh kode ring koran Bali Post Pahan Bali Orti rahina Redite pamijilan JuliDesember warsa 2016, utamin ipun ring rong (kolom) Bencingah. Basa sane kaanggen sajeroning sesuratan koran punika kapanggihin langkungan saking siki basa. Indike sakadi punika nyinahang wenten makudang-kudang fenomena basa sane kaanggen sane medal sajeroning prasasti punika. Indik fenomena sane wenten punika sakadi interperensi, silang kode, lan campuh kode. Cutetnyane pikobet sane pacang katilikin olih panilik mapaiketan sareng murda sajeroning tetilikan.

Sajeroning tetilikan puniki ri sampun kapolihang pikobet-pikobet sane sampun karereh, panilik nureksain malih pikobetpikobet punika antuk ngwatesin pikobet. Tetilikan puniki kawatesin antuk nilikin wantah siki rong (rong) kemanten inggih punika ring rong (rong) bencingah. Parindikan punika boya ja sangkaning ring rong-rong sane lianan nenten wenten pikobet sane mapaiketan sareng tetilikan, nanging indike punika santukan wenten makudang-kudang parindikan sane ngawinang panilik ngwatesin jejering tetilikan puniki. Parindikan punika minakadi tetilikan kabanda antuk galah taler mangda ngicenin galah majeng panilik lianan nglaksanayang tetilikan turmaning maripurnayang tetilikan puniki. Antuk punika pikobet sane pacang katilikin inggih punika indik campuh kode
Bantang pikobet tetilikan:(1) Sapunapi soroh campuh kode sane wenten ring rong Bencingah koran Bali Post Pahan Bali Orti rahina redite sasih Juli-Desember warsa 2016?, (2) Basa napi manten sane wenten ring rong Bencingah koran Bali Post Pahan Bali Orti rahina redite sasih JuliDesember warsa 2016?, (3) Napi sane ngawinang wenten kapanggihin campuh kode ring koran Bali Post Pahan Bali Orti rahina redite sasih Juli-Desember warsa 2016 utamannyane ring rong Bencingah?

Tetujon tetilikan puniki inggih punika minakadi: (1) Mangda prasida nlatarang soroh campuh kode sane wenten ring rong Bencingah koran Bali Post Pahan Bali Orti rahina redite sasih Juli-Desember warsa 2016, (2) Mangda prasida nlatarang basa sane wenten ring rong Bencingah koran Bali Post Pahan Bali Orti rahina redite sasih Juli-Desember warsa 2016, (3) Mangda prasida nlatarang sane ngawinang wenten kapanggihin campuh kode ring koran Bali Post Pahan Bali Orti rahina redite sasih Juli-Desember warsa 2016 utamannyane ring rong Bencingah.

Ring sajeroning tetilikan puniki wenten kawigunannyane, minakadi kawigunan pamucuk lan kawigunan panglimbak sane kabahbahang sakadi ring sor

Kawigunan Pamucuk (teoritis) Kawigunan pamucuk inggih punika kawigunan sane prasida ngicenin pangresep indik pangweruh sane kaunggahang utawi katlatarang ring tetilik. Tetilik puniki kaaptiang prasida ngicenin kawigunan majeng ring panglimbak pangweruh sane sampun sayan anyar utawi modern, utaminyane ngicenin gatragatra sane mapaiketan sareng campuh kode ring basa Bali. Kawigunan Panglimbak (praktis) tetilikan puniki inggih punika minakadi: (1) Majeng ring Pangwacen Tetilikan, pikolih saking tetilikan sumangdane prasida mawiguna ring krama Bali anggen paweweh pangweruh indik campuh kode ring koran Bali Post Pahan Bali Orti rahina Redite sasih Juli-Desember 2016, (2) Majeng ring Panilik siosan Pikolih saking tetilikan puniki prasida dados pratiwimba lan 
pinaka pasaih ri tatkala ngaryanin tetilikan sane masaih, (3) Majeng ring Panyurat koran, Pikolih saking tetilik puniki kaaptiang mangda prasida ngicenin rerawatan utawi tetimbang indik kawentenan sesuratan koran sane madaging campuh kode,(4) Majeng ring Krama Bali, Pikolih saking tatilikan puniki kaaptiang mangda prasida ngicenin pangweruh indik kawentenan campuh kode sane wenten ring sasuratan koran Bali Post pahan Bali orti, sumangdane krama Bali uning indik suksman kawentenan campuh kode ring sasuratan koran Bali Post pahan Bali orti punika.

Sajeroning ngamargiang tetilikan puniki wenten kalih tetilikan sane mapaiketan pinaka panyanding. Tetilikan punika kanggen sasuluh ri kala panilik ngamargiang tetilikan puniki mangda wenten sane kanggen dasar utawi tetimbangan. Tetilikan sane kapertama saking Ni Made Prabandari Listiani (2016) sane mamurda "Campuh Kode sane Wenten ring Rong Bali Orti Koran Bali Post Rahina Redite Pamijilan NovemberDesember Warsa 2015". Tetilikan punika nyantenang indik kawentenan soroh campur kode, sane ngawinang wenten campuh kode lan indik pahan campuh kode sane pinih akeh sane wenten ring rong Bali Orti Koran Bali Post Rahina Redite Pamijilan November-Desember warsa 2015.

Tetilikan sane kaselehin ngenenin indik campuh kode ring pahan Bali Orti koran Bali Post rahina Redite sasih JuliDesember 2016 puniki mahbahang landaasan teori sakadi: Sosiolinguistik, kedwibahasaan (bilingualisme), campuh kode, lan kawentenan media massa.

Kruna sosiolinguistik kakepah dados kalih kruna inggih punika "sosio" lan "linguistik ". Sosio masaih sareng sosial inggih punika sane mapaiketan sareng kauripan parajana, yening linguistik inggih punika widya sane mlajahin indik basa, dadosnyane sosiolinguistik inggih punika pangweruh sane malajahin indik basa sane kaanggen jadma ring pakraman. Sosiolinguistik wantah angkepan kalih pangweruh pantaraning sosiologi miwah linguistik (Aslinda lan Leni, 2007: 6).
Pangweruh sosiologi malajahin indik jadma ring pakraman, dresta miwah pamargin kauripan ring pakraman sane matetujon mangda prasida uning indik tata cara jadma manyama braya ring wewidangan kauripannyane. Pangweruh linguistik malajahin indik basa.

Parinama bilingualisme (Inggris: bilingualism) ring basa Indonesia kasengguh bilingualisme. jadma sane prasida mabebaosan nganggen kalih basa punika kawastanin berdwibasasa utawi dwibahasawan. saking parinama punika prasida kacutetang teges bilingualisme mapaiketan sareng pawigunan kalih basa utawi kalih kode basa. Bilingualisme inggih punika ketahnyane nganggen kalih basa ring sajeroning mabebaosan (intraksi) majeng krama siosan (Nababan, 1991: 27). Lianan ring punika, Manut sakadi sosiolinguistik lan ketahnyane, bilingualisme inggih punika pawigunan kalih basa sane kaanggen olih pawicara sajeroning kauripan anggen jalaran mabebaosan majeng ring anak sane lianan (Aslinda lan Leni, 2017: 8). Riantuk punika, kedwibahasaan (bilingualisme) inggih punika kalih basa sane kaanggen maboas olih pamaos sareng sang sane kairing mabaos manut galah miwah genahnyane.

Campuh kode wantah pasikian utawi can kalih utawi langkungan basa sane kaangen mabebaosan olih kramane. lianan ring punika campuh kode mateges pacampuhan kalih utawi langkung basa utawi soroh basa sane boya ja medal sangkaning genah lan galah sane matutang pamaos mangda nganggen campuh kode saking basa sane lianan (Nababan, 1991: 32).

Soroh-soroh campuh kode wenten kalih inggih punika manut pawiwit basa lan manut wangun kerta basa (Jendra, 2007: 140). Campuh kode manut pawiwit basa kakepah dados tiga inggih punika campuh kode ke tengah, campuh kode ka sisi, lan campuh kode cecampuhan. Campuh kode manut wangun kerta basa kakepah dados tiga inggih punika campuh kode sajeroning wangun kruna, campuh kode sajeroning wangun frase, lan campuh kode sajeroning wangun klausa 
Sane prasida dasar nganggen campuh kode wenten tiga, inggih punika (a) paiketan pawicara, (b) indik kahaan, (c) tetujon pawicara (Jendra, 2007:116). Indike punika malih kacutetang dados kalih, inggih punika sang sane mabaos dados parindikan saking sang sane mabaos lan basa sane kaanggen lan tetujon bebaosan dados parindikan basa

Media masaa inggih punika piranti sane kaanggen ngicenin sakancan orti sane sampun lintang taler orti sane pinih anyar. Media massa mawit saking basa Inggris. Media massa punika ancengnyane (singkatan) saking mass media of communication. "Media massa inggih punika mabebaosan sane nganggen piranti sane prasida kaloktah ring sajebag jagat (seluas-luasnya)" (McQuail 1987: 3). Soroh media massa lumrahnyane wenten kakalih, sesuratan lan elektronik, nanging mangkin wenten sane kabaos media siber utawi media online. Media sesuratan punika imbanyane sakadi koran, majalah, brosur lan sane lianan sakancan sane macetak ring kertas utawi kain. Media elektronik punika sakadi televisi, radio, video,lan sane lianan sakancan sane ring piranti elektronik. Media siber utawi online punika sakadi media sosial, website, portal berita, blog, lan sane lianan sakancan sane mawit saking internet online.

Media massa sesuratan sinalih tunggilnyane inggih punika koran. Koran inggih punika kertas sane kacetak sane madaging orti saking krama, cecirenyane medal manut galahnyane, kahananyane umum, daging ortinyane anyar sane mapaiketan sareng kauripan ring jagat mangda kauningin olih sang pangwacen (Effendy, 2005: 154). Koran prasida kakepah manut galah kamedalang, wentuk, lan kahanan medalnyane (Cangara, 2012: 141). Mawit saking galah koran puniki kamedalang kakepah dados kalih inggih punika koran sadina-dina lan koran awuku". Koran sadina-dina punika koran sane medal nyabran rahina utawi nyabran dina galah semeng utawi sanja, nanging koran awuku punika koran sane medal awuku apisan. Manut wentuknyane, koran kakepah dados kalih inggih punika wenten sane mawentuk plano lan wenten sane mawentuk tabloid. Lan manut kahanan medalnyane prasida kakepah dados kalih inggih punika kahanannyane umum, punika ngicenin orti sane umum majeng ring krama, nanging koran khusus dagingnyane madue ceciren lan pangwacen tertentu minakadi koran Bali Post. Kawigunan koran inggih punika ngicenin orti (informasi), kawigunan mendidik lan kawigunan menghibur.

\section{KRAMANING TETILIKAN}

Manut Wendra (2014: 31), kramaning tetilikan inggih punika dudonan sane kalaksanayang ri tatkala nyawis pikobet sane kalaksanayang. Ring tetilikan puniki wenten makudang-kudang kramaning tetilikan sane kanggen inggih punika sakadi, 1) pendekatan lan soroh tetilikan, 2) wit data, 3) parikrama mupulang data, miwah 4) data tureksa.

Pendekatan lan soroh tetilikan sane kanggen ring tetilikan puniki inggih punika tetilikan deskriptif kualitatif santukan matetujon mahbahang wangun campuh kode ring koran Bali Post Pahan Bali Orti rahina Redite sane ngambil pamijilan JuliDesember warsa 2016, utamin ipun ring rong Bencingah. Tetilikan deskriptif kualitatif mautsaha nyihnayang kasujatian (fakta) utawi fenomena sane wenten ri kala tetilikan punika memargi antuk ngunggahang napi sane sepatutnyane wenten. Ring tetilikan puniki panilik ngambil data antuk ngemargiang tata cara mupulang data sane kadungang sareng data tureksanyane. Lianan ring punika pendekatan deskriptif kualitatif kanggen mangda ngamolihang data sane patut manut kadi kasujatian saking data sane katilikin.

Wit data ring sajeroning tetilikan puniki inggih punika panilik mupulang daging sesuratan koran Bali Post ring rahina Redite pamijilan Juli-Desember warsa 2016, utamin ipun ring rong Bencingah. Salanturnyane, panilik nyalin lengkara-lengkara sane madaging campuh kode ring sesuratan koran Bali Post Pahan Bali Orti rahina Redite pamiji JuliDesember warsa 2016, utamin ipun ring rong Bencingah. 
Parikrama mupulang data sane kaanggen ring tetilikan puniki inggih punika nganggen kalih parikrama minakadi kramaning dokumentasi lan kramaning sadu wicara. Piranti sane kaanggen sajeroning tetilikan puniki inggih punika piranti marupa kartu data sane kaanggen nyorohang data-data sane kaselehin. Lan piranti sadu wicara marupa pitaken sane katujuang ring Pipinan redaksi koran Bali Post miwah piranti marupa HP (handphone) sane kaanggen ngerekam kramaning sadu wicara saking panampen narawakia punika.

Sane kaping untat data tureksa sane kaanggen sajeroning tetilikan puniki inggih punika mastikayang data (identifikasi data), nyorohang data (klasifikasi data), reduksi data lan pamicutet (kesimpulan).

\section{PIKOLIH LAN TETEPASAN}

Pikolih lan tetepasan tetilikan saking tetiga bantang pikobet inggih punika (1) Soroh campuh kode sane wenten ring rong Bencingah koran Bali Post Pahan Bali Orti rahina redite sasih Juli-Desember warsa 2016, (2) Basa sane wenten ring rong Bencingah koran Bali Post Pahan Bali Orti rahina redite sasih Juli-Desember warsa 2016, miwah (3) sane ngawinang wenten kapanggihin campuh kode ring koran Bali Post Pahan Bali Orti rahina redite sasih Juli-Desember warsa 2016 utamannyane ring rong Bencingah.

Campuh kode kabinayang utawi kasorohang dados kalih inggih punika campuh kode manut wit basa lan campuh kode manut kerta basa. Campuh kode manut wit basa kapalih dados tiga inggih punika, campuh kode ka tengah (inner code mixing), campuh kode ka sisi (outer code mixing), campuh kode campuhan (hybrid code mixing). Campuh kode manut kerta basa taler kapalih dados tiga inggih punika campuh kode undagan kruna,campuh kode undagan frasa lan campuh kode undagan klausa (Jendra, 2007: 140).

Sajeroning tetilikan puniki kapolihang 104 data campuh kode manut pawiwit basa. Data-data punika mawit saking 89 data sane marupa campuh kode ka tengah, 11 data sane marupa campuh kode ka sisi lan 4 data sane marupa campuh kode campuhan .Data campuh kode ka tengah sajeroning tetilikan puniki inggih punika sekadi kruna peneliti, akulturasi, kelompok, kayu, leluhur, miwah sane tiosan. Kruna-kruna basa Indonesia sane kapolihang ring sesuratan Bali Orti koran Bali Post rahina redite sasih JuliDesember warsa 2016 utaminipun ring rong bencingah puniki satmaka kruna sane sampun lumrah kanggen ring wangun bebaosan basa Bali. Sekadi kruna "peneliti" ring sesuratan koran Bali Post Pahan Bali Orti rahina redite sasih JuliDesember warsa 2016 sane wenten ring rong Bencingah, kruna punika sepatutnyane prasida kagentosin antuk kruna "panilik" ring basa Bali, nanging sang pangawi utawi panyurat orti nenten ngentosin kruna punika santukan kruna "peneliti" sane pinih kaloktah kanggen olih krama.

Tiosan malih wenten kruna "akulturasi" ring sesuratan koran Bali Post Pahan Bali Orti rahina redite sasih JuliDesember warsa 2016 sane wenten ring rong Bencingah, kruna "akulturasi" puniki nenten prasida kagentosin antuk kruna ring basa Bali santukan kruna punika nenten madue padanan ring basa Bali, punika sane ngawinang sang pangawi utawi panyurat orti ngawigunayang kruna "akulturasi" sakadi wangun wit basanyane. Akeh kapanggihin pikolih data campuh kode sane nenten madue padanan kruna ring basa Bali sakadi, teknologi, kontenporer, kreatif miwah sane tiosan. Ring tetilikan puniki, campuh kode ka tengah wantah basa Indonesia sane pinih akeh (didominasi bahasa Indonesia) sakewanten basa punika akehan marupa basa serapan saking basa Inggris. Saha ring tetilikan puniki sane pinaka tetimbangan (pedoman) rikala milah campuh kode punika kacingak saking sasuratannyane.

Data-data campuh kode ka sisi sane kapolihang punika sami mawit saking basa Ingris, sakadi kruna fashion, import, mood, guide miwah sane tioasan. Krunakruna basa Inggris sane kapolihang ring tetilikan puniki wantah marupa kruna basa 
umum sane sampun ketah kauningin boya ja olih krama Bali kemanten nanging olih jadma ring sajebag jagat santukan pinaka basa Internasional. Sekadi pikolih kruna fashion, import, mood, lan guide, kruna punika sampun ketah kanggen ring pantaraning wangun bebaosan krama pamekasnyane krama Bali.

Rauhnyane basa-basa dura negara ka Bali gelis pisan kasenengin olih krama, nanging kawentenan ipun nenten ngawinang samian krama prasida nganggen utawi mabasa dura negara. Kasujatiannyane akeh krama sane durung tatas uning sareng basa dura negara sane kasenengin. Indike punika sane ngawinang krama pamekasnyane para yowana nangingin basa-basa dura negara ring wangun bebaosan basa Bali mangda sinah ipun sampun nginutin panglimbak zaman sane wenten mangkin. Kawentenan punika taler sane ngawinang ring pahan Bali Orti koran Bali Post Pahan Bali Orti redite sasih Juli-Desember warsa 2016 wenten kapanggihin basa-basa dura negara sane kacihnayang antuk pikoloh data soroh campuh kode ka sisi sane mawit saking basa Inggris.

Data-data campuh kode campuhan sane kapolihang punika sami mawit saking basa Indonesia lan basa Ingris. Data campuh kode campuhan puniki wenten ring siki lengkara sakadi imbanyane ring data sane kapertama wenten kruna modifikasi, mode lan fashion. Kruna-kruna sane kapolihang ring tetilikan puniki wantah marupa kruna basa umum sane sampun ketah kauningin boya ja olih krama Bali kemanten nanging olih jadma ring sajebag panagara Indonesia puniki, lan kruna punika sampun ketah kanggen ring pantaraning wangun bebaosan krama pamekasnyane krama Bali. Kawentenan punika taler sane ngawinang ring koran Bali Post Pahan Bali Orti rahina redite sasih Juli-Desember warsa 2016 wenten kapanggihin basa-basa campuhan saking basa Indonesia lan basa dura negara sane kacihnayang antuk pikoloh data soroh campuh kode campuhan sane mawit saking basa Indonesia lan basa Inggris.

Data campuh kode manut kerta basa kapolihang 110 data sane mawit saking 94 data campuh kode undagan kruna, 13 data campuh kode undagan frasa lan 3 data marupa campuh kode undagan klausa. Campuh kode undagan kruna sane sampun kapolihang ring tetilikan puniki. Maka samian data campuh kode undagan kruna punika wantah marupa kruna-kruna sane mawit saking basa sane matiosan. Indike punika kasinahang antuk makudang-kudang pikolih data campuh undagan kruna sekadi, fashion, import, mood, guide peneliti, akulturasi, kelompok, kayu miwah akeh pikolih campuh kode undagan kruna sane tiosan. Pikolih data campuh kode punika samian marupa wangun kruna sekadi imbanyane data "kayu" sane marupa wangun kruna ring basa Indonesia, lan data "fashion" sane marupa wangun kruna ring basa Inggris. Wentuk campuh kode sane ketah kauninging olih krama inggih punika marupa wangun kruna. Ring wangun bebaosan basa Bali sane nganggen campuh kode, akehan krama Bali sane nganggen campuh kode wantah ring wangun kruna dwaning wangun punika sane pinih dangan kacampuhin ring lengakara bebaosan.

Campuh kode undagang kruna akeh kanggen olih sang pengawi utawi panyurat orti Bali dwaning toisan saking nenten wenten kruna sane sepadan taler mangda dangan karesepang olih krama utawi sang sane ngwacen orti punika.

Data campuh kode undagan frasa sakadi, dana motivasi, kewajiban moral, Guide Freelance, miwah sane tiosan. Maka samian data punika munggah ring soroh campuh kode undagan frasa santukan kawangun antuk kalih kruna sane nenten madue linging manut panampen sujana ring sane kaunggahang ajeng. Sakadi data "Guide Freelance", data punika kawangun antuk kalih kruna mawit saking basa Inggris. Tiosan malih sakadi data "kewajiban moral", data punika kawangun kalih kruna sane mawit saking basa Indonesia.

Wangun frasa madue wentuk sane agengan saking wangun kruna, indike punika pateh sareng campuh kode undagan frasa sane madue wentuk agengan saking campuh kode undagan 
kruna. Campuh kode undagan frasa kawangun antuk kalih utawi langkung kruna campuh kode sane prasida mawit saking siki utawi kalih soroh basa campuh kode. Punika sane ngawinang campuh kode ring undagan puniki meweh kanggen ring wangun bebaosan yening nenten madue pangresep sane becik pisan ring soang-soang basa sane kauningin. Tiosan ring punika, soroh campuh kode undagan frasa arang kanggen olih krama, santukan wangun campuh kode puniki meweh kacampuhin ring pantaraning wangun bebaosan. Dadosnyane manut pikolih lan tetepasan sane sampun katlarang ring ajeng prasida kacutetang, iusan campuh kode undagan frasa ring koran Bali Post Pahan Bali Orti sasih Juli-Desember warsa 2016 nenten dahat sakadi campuh kode undagan kruna santukan data sane kapolihang nenten akeh pisan.

Data campuh kode undagan klausa sakadi,alih fungsi lahan, vaksin anti rabies, lan me on history. Maka samian data punika munggah ring soroh campuh kode undagan klausa santukan sampun kawangun antuk jejring lan lingin. Sakadi data "alih fungsi lahan", data punika sampun kawangun antuk jejering lan linging. Kruna "alih" pinaka jejering lan kruna "fungsi" pinaka linging. punika Tiosan malih sakadi data "kewajiban moral", data punika kawangun kalih kruna sane mawit saking basa Indonesia.

Wangun klausa madue wentuk sane pinih tegeh saking wangun kruna lan wangun frasa. Campuh kode undagan klausa sakirang-kirangnyane kawangun antuk jejering lan linging sane prasida mawit saking siki utawi kalih soroh basa campuh kode. Punika sane ngawinang campuh kode ring undagan puniki meweh kanggen ring wangun bebaosan yening nenten madue pangresep sane becik pisan ring soang-soang basa sane kauningin. Tiosan ring punika, soroh campuh kode undagan klausa arang kanggen olih krama, santukan wangun campuh kode puniki meweh kacampuhin ring pantaraning wangun bebaosan. Dadosnyane manut pikolih lan tetepasan sane sampun katlarang ring ajeng prasida kacutetang, iusan campuh kode undagan klausa ring koran Bali Post Pahan Bali Orti sasih Juli-Desember warsa 2016 nenten dahat sakadi campuh kode undagan kruna santukan data sane kapolihang akidik pisan.

Basa-basa sane ngawinang wenten kapanggihin campuh kode ring koran Bali Post Pahan Bali Orti rahina redite sasih Juli-Desember warsa 2016 inggih punika Basa Bali, Basa Indonesia lan Basa Inggris. Data indik basa sane kaanggen sajeroning koran Bali Post pamekasnyane ring koran Bali Post Pahan Bali Orti rahina redite sasih Juli-Desember warsa 2016 kapolihang antuk ngwacen lan nyelehin koran-koran sane koran Bali Post Pahan Bali Orti rahina redite utaminipun ring sasih Juli-Desember warsa 2016.

Sane kapertama ngenenin indik basa Bali. Ring koran Bali Post Pahan Bali Orti pamekas ring sasih Juli-Desember warsa 2016 sampun prasida kacingak akeh pisan basa Bali sane kaanggen riantukan basa Bali ring koran punika pinaka Basa utama ring sajeroning sesuratan koran. Basa Bali sane kaanggen inggih punika basa Bali Alus sane wenten kadagingin basa Bali lumrah. Kadagingin basa Bali lumrah pinaka jalaran mangde krama utawi sang sane ngwacen koran punika dangan ngresepnag sakancan orti sane kasurat. Pinaka imbanyane sakadi: Rikala makarya banten caru mangda nenten nganggen siap Bali sane sangkur utawi siap sane nenten madue ikuh. Saking sinalih tunggil imba punika majanten sampun sang sane ngwacen koran utawi orti dangan ngresepang daging orti punika.

Sane kaping kalih basa Indonesia. Ring koran Bali Post Pahan Bali Orti pamekas ring sasih Juli-Desember warsa 2016 taler kapolihang akeh nganggen basa Indonesia. Imbanyane sakadi: Prof. Dr. Wayan P. Windia S.H., M.Si., Guru Besar Bidang Hukum Adat Bali maosang, kahanan punika minab sangkaning pawiwahan adat Bali sané kamargiang wantah ngranjing ring pawiwahan adat Bali sané "dilarang" miwah sané "tidak dikehendaki". Saking imba punika nyihnayang sang sane nyurat orti utawi koran madue pikayun mangdane krama 
sane ngwacen koran utawi orti punika nenten meweh ngresepang sakacan daging orti ring koran sane kasurat. Sakadi imba ring ajeng, yening lengkara punika sami nganggen basa Bali nenten kacampuhin antuk basa Indonesia sinah pangwacen pacang meweh ngresepang daging orti punika.

Sane kaping tiga utawi kaping untat inggih punika basa Inggris. Ring koran Bali Post Pahan Bali Orti pamekas ring sasih Juli-Desember warsa 2016 lianan ring basa Bali lan basa Indonesia taler wenten basa Inggris sane kaanggen. Imbanyane: Dané sané taler dados Guide Freelance puniki malih maosang, pakaryan nyusun kalénder punika wantah pakaryan sané patut kamargiang sangkaning nganutin mood utawi nénten dados kadropon. Saking imba punika nyihnayang basa Inggris taler kawigunayang ring sajeroning koran Bali Post pahan Bali Orti sane mijil ring rahina redite sasih Juli-Desember warsa 2016.

Sane pinaka dasar nganggen campuh kode wenten tiga, inggih punika (a) paiketan pawicara, (b) indik kahaan, (c) tetujon pawicara (Jendra, 2007:116). Maka tiga punika prasida kapalih malih dados kalih inggih punika indik pawicara lan indik kabasan. Dadalan saking pawicara prasida kacingak ri tatkala sang pawicara ngangen basa daerah sane kaselagin antuk basa siosan sakadi basa Indonesia pastika sampun punika dados campuh kode.

Kawentenan campuh kode ring koran Bali Post Pahan Bali Orti rahina redite sasih Juli-Desember warsa 2016 prasida kapolihang antuk nglaksanayang sadu wicara. Sadu wicara punika kamargiang sareng dane Bapak I Nyoman Wirata sane pinaka Pimpinan Redaksi ring Bali Post. Sadu wicara puniki kalaksanayang ring kantor Bali Post sane magenah ring margi Kepundung 6A Denpasar. Ring sajeroning sadu wicara punika kamargian antuk ngunggahang 5 pitaken sane mapaiketan sareng pikobet sane kapolihang sajeroning nilikin campuh kode ring koran Bali Post Pahan Bali Orti rahina redite sasih Juli-Desember warsa 2016 puniki. Saking limang pitaken sadu wicara, kapolihang makudang-kudang panampen saking narawakya sane katepasin manut seseleh lan teori sane wenten mangdane sinah parindikan sane ngawinang wentenyane basa campuhan (campur kode) ring sesuratan Bali Orti koran Bali Post rahina redite sasih JuliDesember warsa 2016.

Saking prikrama sadu wicara punika prasida kapolihang data sane ngawinang wenten kapanggihin campuh kode punika: a) sangkaning kawentenan (keterbatasan) ring basa), indike punikasane ngawinang nenten samian kruna-kruna saking basa Indonesia punika dados kaanggen basa Bali, wenten krunakruna saking basa Indonesia sane nenten wenten padanan utawi kruna sane masaih sareng basa Bali, dadosnyane krunakruna saking basa Indonesia punika sane kaanggen. b) Sane kaping kalih, pacampuhan basa punika sampun lumrah kauningin lan kaanggen olih kramane ring Bali.

Indike punika nyihnayang yening campuh kode punika sampun prasida katampi ring tengahing kahuripan krama Bali lan sampun prasida dados basa sarahina (bahasa Pergaulan). c) Sane kaping tiga, mangda dangan karesepang. Yening nganggen basa bali sane alus (Basa Alus singgih) sinah krama utawi sang sane ngwacen orti punika meweh ngresepang sakancan daging orti sane kasurat, santukan nenten samian krama Bali sane waged lan uning mabasa Bali. Saha pawesane sane ngawinang panyurat ngangge campuh kode wantah saking widang Pendidikan. Pendidikan prasida nyihnayang kawagedan pamaos utawi ring tetilikan puniki panyurat koran, yening pamaos punika waged ring sajeroning mabasa pastika akidik pacampuhan basa sane kaanggen nanging yening nenten waged pastika akeh basa-basa campuhan utawi basa-basa siosan ring sajeroning bebaosannyane. Ring tetilikan puniki prasida kabaosang akidik pacampuhan basa sane kaanggen santukan ring soangsoang koran punika kirang langkung wantah $4,5 \%$ sane madaging campuh kode. Dadosnyane, sane ngawinang wenten kapanggihin campuh kode ring 
koran Bali Post Pahan Bali Orti rahina redite sasih Juli-Desember warsa 2016 puniki wantah tetujon saking panyurat orti mangda daging sakancan orti sane kasurat punika prasida dangan karesepang lan prasida ngawi pangwacen seneng ngawcen orti-orti sane kasurat ring Bali Orti.

\section{PAMUPUT}

Saking pikolih lan tetepasan sane sampun kabahbahang ring ajeng, prasida katingkesang indik campuh kode manut wit basa kapolihang 104 data, data-data punika kapalih dados tiga inggih punika mawit saking 90 data campuh kode ka tengah, 11 data campuh kode ka sisi lan 3 data campuh kode campuhan. Campuh kode manut undagan kruna kapolihang 110 data. Data-data punika prasida kakepah dados tiga inggih punika mawit saking 94 data campuh kode undagan kruna, 13 data campuh kode undagan frasa lan 3 data campuh kode undagan klausa.

Ring koran Bali Post Pahan Bali Orti sasih Juli-Desember warsa 2016 kapolihang wenten tetiga basa sane kaanggen, inggih punika basa Bali, basa Indonesia lan basa Inggris. Ring sajeroning pikolih puniki kakantenang akehan Basa Bali sane kaanggen, santukan Basa Bali pinaka basa utama sane kaanggen nyurat orti-orti ring koran punika.

Parindikan sane ngawinang wentenyane kapanggihin campuh kode ring koran Bali Post Pahan Bali Orti sasih Juli-Desember warsa 2016 manut pikolih sadu wicara sane sampun kaselehin ring tetilikan puniki wenten tiga inggih punika a) sangkaning kawentenan (keterbatasan) ring basa), b) Sane kaping kalih, pacampuhan basa punika sampun lumrah kauningin lan kaanggen olih kramane ring Bali. c) Sane kaping tiga, mangda dangan karesepang. Saha pawesana sane ngawinang campuh kode inggih punika widang pendidikan.

Piteket kawedarang majeng ring: (1) Majeng ring pangwacen tetilikan kaptiang mangda prasida ngawigunanyang parindikan campuh kode sane patut ring

sajeroning bebaosan, mangda prasida nincapang kawagedan ri kalaning mabebaosan nganggen basa Bali utawi nganggen campuh kode ring sajeroning kahuripan. (2) Majeng ring panilik sane lianan kaptiang mangda prasida nglanturang saha nglimbakang tetilikan puniki. Panglimbak sane kaptiang inggih punika nglaksanayang tetilik asoroh lan prasida maripurnayang tetilikan puniki mangda sayan mawiguna sajeroning nglimbakang kawentenan basa Bali. (3) Majeng ring panyurat koran Bali Orti, kaptiang mangda ngawigunayang kawentenan campuh kode sane becik tur patut nganutin kawentenan lan suksma Orti Bali sane madasar antuk basa Bali. Dadosnyane kawentenan campuh kode ring sesuratan Bali Orti mangda nenten nglangkungin kawentenan basa Bali sane pinaka basa utama ring sajeroning Bali Orti punika. Mangdane kawentenan koran mabasa Bali punika prasida kadadosang silih sinunggil jalaran nglestaring basa Bali. (4) Majeg ring krama Bali, kaptiang krama Bali stata eling sareng tetemian panglingsir sinalih tunggilnyane Basa Bali mangda basa bali punika stata ajeg nenten kagentosin antuk basa-basa sane siosan sane sampun ngranjing ring tengahin krama sakadi mangkin. Lianan ring punika mangda prasida nguningin kawingunan lan suksman saking kawentenan campuh kode punika mangda krama Bali nenten iwang ring sajeroning ngawigunayang parindikan campuh kode.

\section{DAFTAR PUSTAKA}

Aslinda lan Leni Syafyahya. 2007. Pengantar Sosiolinguistik.

Bandung: PT Refika Aditama.

Awe. 2003. http: ejournal.ilkomfisifunmul.ac.id (akses 5september 2017).

Cangara, Hafied. 2012. Pengantar IImu Komunikasi. Jakarta: PT Raja Grafindo Persada.

Effendy, Onong Uchjana. 2005. IImu Komunikasi: Teori dan Praktek. Bandung: PT Remaja Rosdakarya Offset.

Jendra, I Wayan. 2007. Sosiolinguistik Teori dan Penerapannya. Surabaya: Paramita. 
Listiani, Ni Made Prabandari. 2016. Canpuh Kode sane Wenten ring Rong Bali Orti Koran Bali Post Rahina Redite Pamijilan November-Desember Warsa 2015. Skripsi (nenten kamijilang). Singaraja: Universitas Pendidikan Ganesha.

MOlcQuail, Denis. 1987. Teori Komunikasi Masa. Jakarta: Erlangga.

Nababan, P.W.J. 1991. Sosiolinguistik Suatu Pengantar. Jakarta: PT Gramedia Pustaka Utama.

Utami, Gusti Ayu Putu Novi Widya. 2015. Campuhan Pralambang Basa (Campur Kode) ring Rubrik Bali Orti Koran Bali Post Pamijilan Oktober-Desember 2014. Skripsi (nenten kamijilang). Singaraja: Universitas Pendidikan Ganesha.

Wendra, I Wayan. 2014. Buku Ajar Penulisan Karya IImiah. Singaraja: Universitas Pendidikan Ganesha.

Wijana, I Dewa Putu. 2012. Sosiolinguistik Kajian Teori dan Analisis. Yogyakarta: Pustaka Pelajar. 